\title{
Synthesis of Carbon Nanotube/Graphene Composites by One-Step Chemical Vapor Deposition for Electrodes of Electrochemical Capacitors
}

\author{
Chuen-Chang Lin and Yi-Wei Lin \\ Department of Chemical \& Materials Engineering, National Yunlin University of Science and Technology, \\ 123 University Road, Section 3, Douliu, Yunlin 64002, Taiwan
}

Correspondence should be addressed to Chuen-Chang Lin; linchuen@yuntech.edu.tw

Received 26 January 2015; Revised 24 March 2015; Accepted 24 March 2015

Academic Editor: Bong-Gill Choi

Copyright (C) 2015 C.-C. Lin and Y.-W. Lin. This is an open access article distributed under the Creative Commons Attribution License, which permits unrestricted use, distribution, and reproduction in any medium, provided the original work is properly cited.

To control the packing density of carbon nanotubes (CNTs) and the number of graphene layers, carbon nanotube/graphene composites are directly grown on cobalt $(\mathrm{Co})$ catalysts-coated nickel foam by one-step ambient pressure chemical vapor deposition (CVD) at different temperatures and times. The carbon nanotube/graphene composites grown by one-step CVD at $850^{\circ} \mathrm{C}$ for $10 \mathrm{~min}$ possess the highest specific capacitance. Furthermore, a lower growing temperature leads to a higher packing density of CNTs and a smaller number of layers of graphene. A shorter growing time also leads to a smaller number of layers of graphene.

\section{Introduction}

Electrochemical capacitors are charge-storage devices which possess a higher power density and a longer cycle life than batteries $[1,2]$. Their applications include power sources for hybrid vehicles, starting power for fuel cells, and burstpower generation in electronic devices [3-7]. Electrochemical capacitors are classified into two types, electric double layer capacitors (EDLC) and pseudocapacitors according to the energy-storage mechanisms. The capacitance of an EDLC arises from the separation of charge at the interface between the electrode and the electrolyte. However, pseudocapacitance arises from redox reactions of electroactive materials with several oxidation states [1, 8-12].

CNTs have nanometer size, hollow structure, low ratio of micropores, high accessible surface area, low resistance, and high stability [13]. Graphene has higher accessibly specific surface area compared with CNTs as well as activated carbon and higher conductivity compared with activated carbon as well as CNTs [14-16]. These properties make them potentially suitable for fabrication of electrodes in electrochemical capacitors.
The densities of CNTs grown on Fe, Co, and Ni catalysts are $4 \times 10^{9} 1 / \mathrm{cm}^{2}, 4 \times 10^{9} 1 / \mathrm{cm}^{2}$, and $2 \times 10^{9} 1 / \mathrm{cm}^{2}$, respectively, due to the easy agglomeration of the small sized Ni particles compared with $\mathrm{Fe}$ or Co particles [17]. Furthermore, Co catalysts have shown the highest intensity ratio of the C-C stretching mode to the disorder-induced mode of graphite structure for carbon products at lower temperatures [18]. Therefore, in this study, CNTs were grown on Co (catalysts) in order to minimize amorphous carbon formation and achieve a higher density of CNTs, thus producing higher electrochemical stability. The capacitive properties of graphene films depended on the number of graphene layers, and the graphene films with three layers possessed low chargetransfer resistance as well as higher specific capacitance than those of thicker graphene films due to the close attachment of graphene films on the Ni substrate [19]. Too high carbon supply rate leads to increasing defect density of graphene and thicker graphene results from higher growth temperature [20]. Bilayer graphene can be synthesized by CVD on polycrystalline $\mathrm{Ni}$ films and the average defect density decreases with the increasing growing time [21]. Thickness of graphene films can be controllably synthesized by chemical 
vapor deposition (CVD) on polycrystalline copper and the number of layers of graphene increases with the increasing growing time and temperature [22].

The layer spacing between the graphene nanosheets controlled through interacting function nanocarbons such as CNTs might be crucial for enhancement of the storage capacity [23]. The CNTs can act as the spacer in fabricating a three-dimensional hierarchical structure with graphene sheets, thus enhancing its effective surface area and capacitance performance [24]. The multiwalled carbon nanotubes in the graphene/multiwalled carbon nanotube film can efficiently increase the basal spacing and bridge the defects for electron transfer between graphene sheets, thus increasing electrolyte/electrode contact area and facilitating transportation of electrolyte ion as well as electron into the inner region of electrode [25]. Three-dimensional CNTs/graphene sandwich structures with CNTs pillars grown in between the graphene layers were prepared by CVD and the unique structure possessed the high-rate transportation of electrolyte ions as well as electrons throughout the electrode matrix since the introduction of CNTs can provide diffusion path for electrolyte ions on the surface of graphene and the interconnection of CNTs with graphene can form a conductive network for the transport of electrons [26]. Carbon nanofibers were grown by CVD on graphene sheets synthesized by a modified Hummers method; the carbon nanofibers with many cavities and open tips as well as edges of exposed graphene platelets can be homogeneously distributed in between the graphene sheets as spaces to separate the neighboring graphene and be beneficial for fast ion/electron transfer as well as sufficient contact between active materials as well as electrolyte [27]. Vertically aligned CNTs were directly grown by CVD (60 sccm $\mathrm{C}_{2} \mathrm{H}_{2}, 120 \mathrm{sccm} \mathrm{H}$, and $200 \mathrm{sccm} \mathrm{Ar}, 750^{\circ} \mathrm{C}$ ) on graphene paper coated with Fe as well as $\mathrm{Al}_{2} \mathrm{O}_{3}$ and a higher as well as more stable discharge capacity compared with graphene paper as well as CNTs was achieved [28]. Graphene films were grown on copper foil by low pressure CVD (20 torr, $1000^{\circ} \mathrm{C}$, and $100 \mathrm{sccm} \mathrm{CH}_{4}, 200 \mathrm{sccm} \mathrm{H}_{2}$, and $200 \mathrm{sccm} \mathrm{Ar}$ ), then functionalized with 1-pyrenebutyric acid by drop casting, and coated with multiwalled carbon nanotubes by drop casting after functionalization [29]. Hybrid CNTs and graphene nanostructures were directly grown by ambient pressure chemical vapor deposition (CVD); methane was introduced to form graphene on copper foils at $950^{\circ} \mathrm{C}$, then Fe catalysts were deposited on graphene/copper foils by ebeam evaporation, and ethylene was next introduced to grow pillar CNTs on graphene/copper foil at $750^{\circ} \mathrm{C}$ [30]. The CNTs-graphene hybrid materials were grown by simple one-step ambient pressure CVD on copper foil spin-coated with silicon nanoparticles using ethanol as precursor at different temperatures and the density of CNTs can be controlled by the CVD growth temperature [31]. The CNTsgraphene hybrid materials were synthesized on an oxygenplasma treated copper film coated with Fe catalysts by ebeam evaporation through a one-step CVD process using a mixture of acetylene and hydrogen at 650 torr for 10 to $20 \mathrm{~min}$ [32]. Vertically grown multiwalled CNTs on a single-layer graphene floor were synthesized by a one-step acetyleneCVD process on copper foil (catalysts for graphene growth)

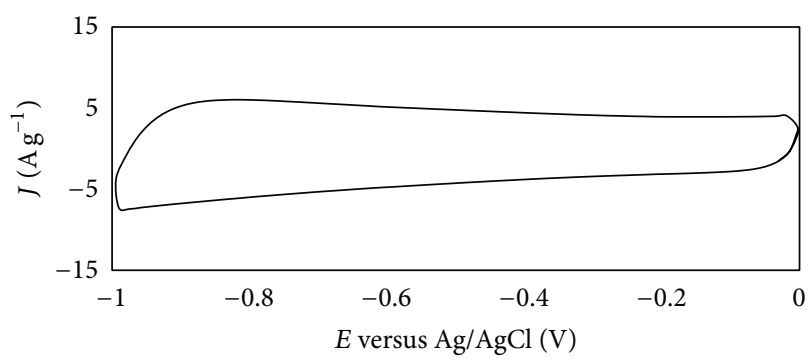

FIgURE 1: The CV curve at a potential scan rate of $100 \mathrm{mV} / \mathrm{s}$ in a $6 \mathrm{M}$ $\mathrm{KOH}$ solution for carbon nanotube/graphene composites grown by one-step CVD for $10 \mathrm{~min}$ at $850^{\circ} \mathrm{C}$.

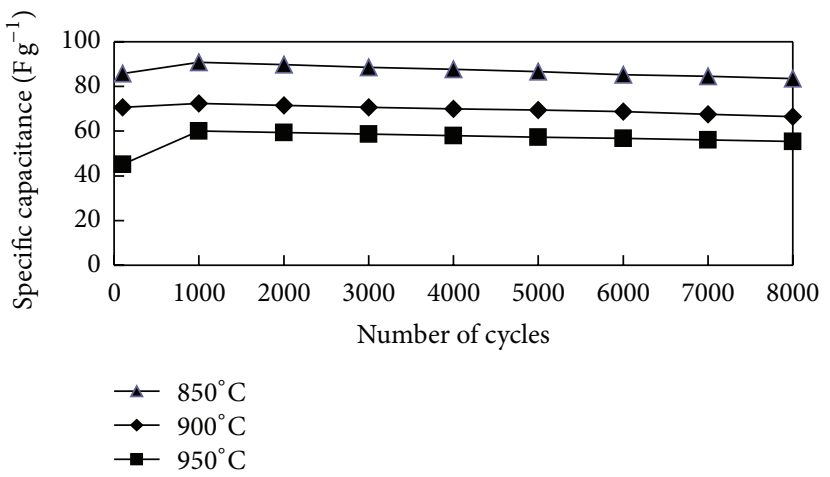

FIGURE 2: The effects of carbon nanotube/graphene composites grown by one-step CVD for $10 \mathrm{~min}$ at different growing temperatures $\left(850,900\right.$, and $\left.950^{\circ} \mathrm{C}\right)$ on specific capacitance.

coated with $\mathrm{Fe}$ (catalysts for multiwalled CNTs growth) by e-beam evaporation [33]. To increase the accessibly specific surface area and the stability as well as conductivity between the carbon nanotube bundles as well as the nickel foam, threedimensional few layer graphene/multiwalled carbon nanotube architectures were fabricated on oxygen-plasma treated nickel foam coated with Fe catalysts by e-beam evaporation through a one-step ambient pressure CVD process using a mixture of acetylene and hydrogen [34]. Therefore, in order to control the packing density of CNTs and the number of graphene layers, carbon nanotube/graphene composites were fabricated on hydrogen-annealed nickel foam coated with Co catalysts by radio frequency (RF) magnetron sputtering through a one-step ambient pressure CVD process at different temperatures and times in this research.

\section{Materials and Methods}

Nickel foam with three-dimensional conductive network structure working as template for the growth of graphene facilitated easy access of electrolyte ions to electrode surface and hence increased the active material utilization of the electrode and then the specific capacitance of the electrode with the $\mathrm{Ni}$ foam current collector was higher than that with the Ti mesh current collector $[35,36]$. The nickel foam $\left(1 \times 2 \mathrm{~cm}^{2}\right)$ was degreased ultrasonically in acetone until any surface grease was completely eliminated. Next, it was rinsed 


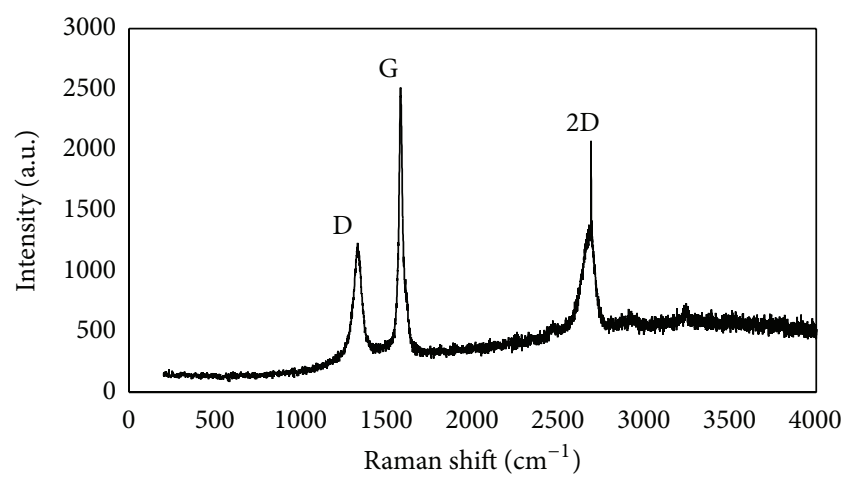

(a)

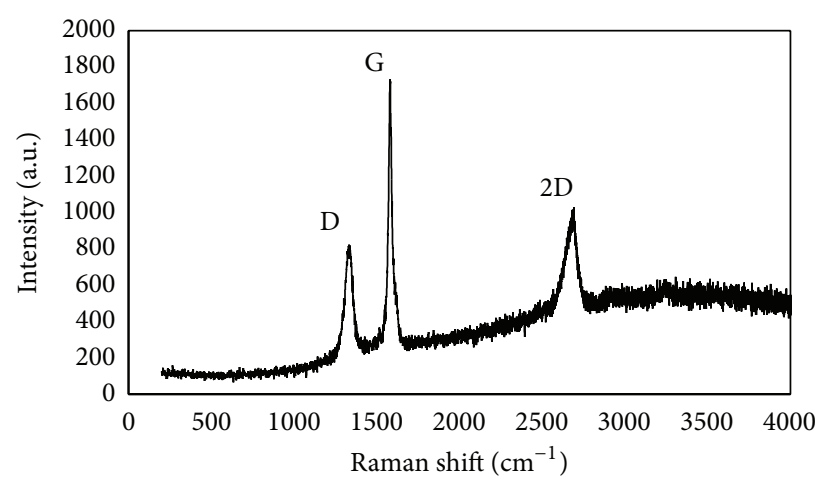

(b)

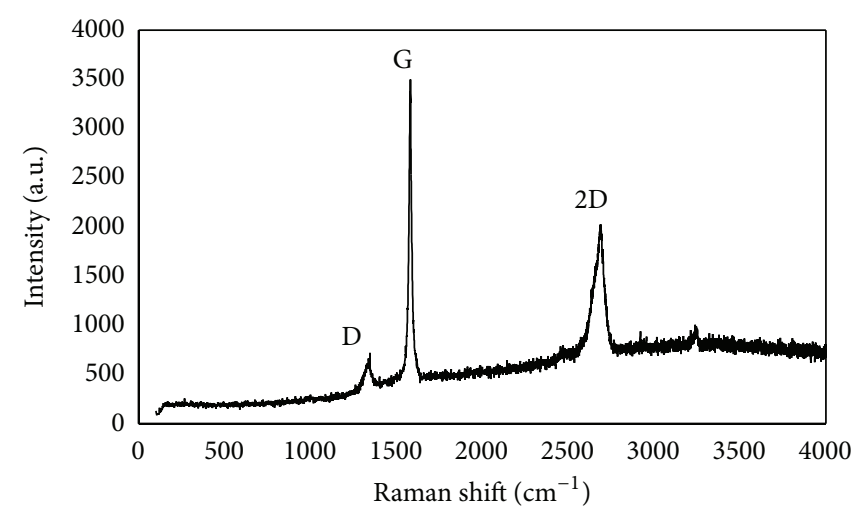

(c)

FIGURE 3: Raman spectra of carbon nanotube/graphene composites grown by one-step CVD for 10 min at different growing temperatures ((a) $850^{\circ} \mathrm{C}$, (b) $900^{\circ} \mathrm{C}$, and (c) $950^{\circ} \mathrm{C}$ ).

with pure deionized water and then oven-dried in air $\left(50^{\circ} \mathrm{C}\right)$ to constant weight.

Carbon nanotube/graphene composites were grown by one-step ambient pressure CVD. First, the pretreated nickel foam substrate was heated at $1000^{\circ} \mathrm{C}$ in $\mathrm{H}_{2}(100 \mathrm{sccm})$ and $\operatorname{Ar}(250 \mathrm{sccm})$ for $10 \mathrm{~min}$ to reduce the surface oxide layer. Next, before carbon nanotube/graphene composites growth, the Co catalyst particles were deposited on the pretreated and annealed nickel foam substrate by RF magnetron sputtering from a 3-inch disk Co target (purity: $99.9 \%$, purchased from SCM, INC) in a vacuum chamber with a background pressure of $7 \times 10^{-6}$ torr. The distance between the target and the substrate was $10 \mathrm{~cm}$. The sputtering power, sputtering pressure, sputtering time, and the volume flow rate of argon were maintained at $50 \mathrm{~W}, 5 \mathrm{mtorr}, 5 \mathrm{~min}$, and $25 \mathrm{sccm}$, respectively. Finally, carbon nanotube/graphene composites were grown on the annealed as well as Co-coated nickel foam using thermal chemical vapor deposition (CVD) with a gas mixture of $\mathrm{C}_{2} \mathrm{H}_{2}(15 \mathrm{sccm})$ and $\mathrm{H}_{2}(100 \mathrm{sccm})$ as well as $\mathrm{Ar}(400 \mathrm{sccm})$ at different temperatures $\left(850,900\right.$, and $\left.950^{\circ} \mathrm{C}\right)$ as well as times $(10,15$, and $20 \mathrm{~min})$ and then by cooling to ambient temperatures at a rate of $10^{\circ} \mathrm{Cmin}^{-1}$ in Ar with the same volume flow rate as carbon nanotube/graphene composites grown.

Electrochemical measurements for the prepared carbon nanotube/graphene composite electrodes were performed using an electrochemical analyzer $(\mathrm{CH}$ Instruments $\mathrm{CHI}$ $608 \mathrm{~B}, \mathrm{USA}$ ). The three-electrode cell consisted of $\mathrm{Ag} / \mathrm{AgCl}$ as the reference electrode, $\mathrm{Pt}$ as the counter electrode, and the prepared carbon nanotube/graphene composite electrodes as the working electrode. The electrolytes were degassed with purified nitrogen gas before voltammetric measurements and nitrogen was passed over the solution during all the measurements. The solution temperature was maintained at $25^{\circ} \mathrm{C}$ by means of circulating water thermostat (HAAKE DC3 and K20, Germany). The cyclic voltammetry (CV) was undertaken with a $6 \mathrm{M}$ aqueous electrolyte $(\mathrm{KOH})$ since the high $\mathrm{KOH}$ concentration led to high capacitance, low internal resistance, and a narrow voltage window for activated carbon electrodes [37]. A CV scan rate of $100 \mathrm{mV} \mathrm{s}^{-1}$ in the range $-1 \sim 0 \mathrm{~V}$ was used in all measurements except where stated. Capacitance is normalized to $1 \mathrm{~g}$ of the carbon nanotube/graphene composites except where stated:

$$
C=\frac{1}{m \Delta V S} \int i d V
$$

where $m$ is the mass of the carbon nanotube/graphene composites, $\Delta V$ is the potential window, $S$ is the scan rate, and $\int i d V$ is the integrated area of the CV curve.

Chronopotentiometry $(\mathrm{CP})$ was undertaken with varying currents $(1,3$, and $5 \mathrm{~mA})$. 


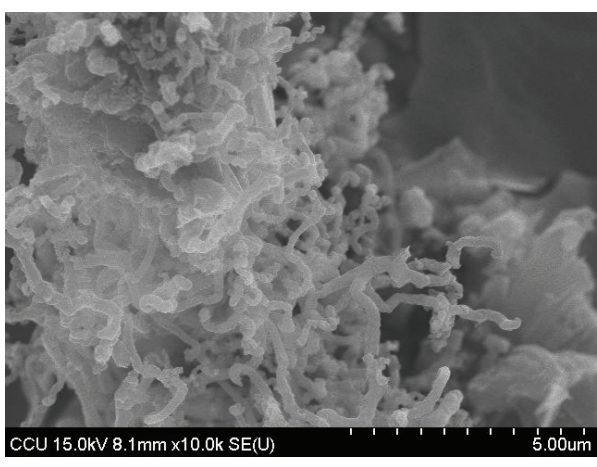

(a)

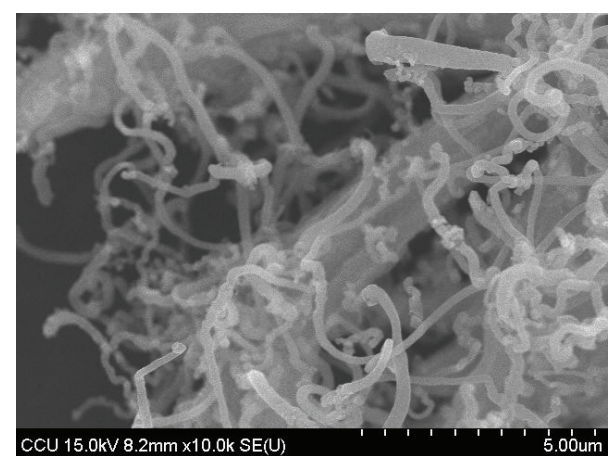

(b)

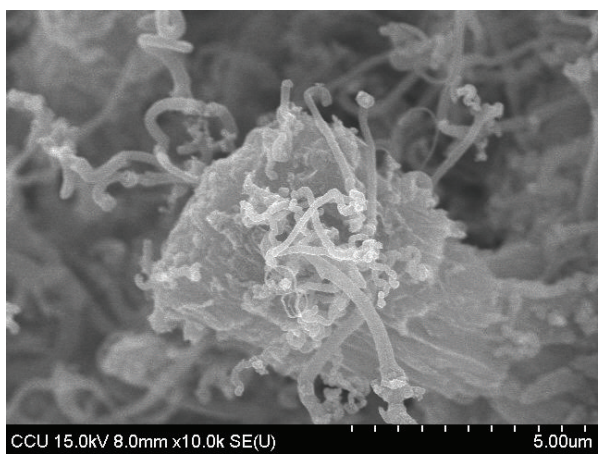

(c)

FIGURE 4: The FESEM images of carbon nanotube/graphene composites grown by one-step CVD for 10 min at different growing temperatures ((a) $850^{\circ} \mathrm{C}$, (b) $900^{\circ} \mathrm{C}$, and (c) $950^{\circ} \mathrm{C}$ ).

The packing density of CNTs for carbon nanotube/ graphene composites grown at different temperatures as well as times and the thickness of the carbon nanotubes for the carbon nanotube/graphene composite grown for $10 \mathrm{~min}$ at $850^{\circ} \mathrm{C}$ were conducted by field emission scanning electron microscope (FE-SEM: JEOL JSM-6700F, Japan). Furthermore, the $I_{2 \mathrm{D}} / I_{\mathrm{G}}$ for carbon nanotube/graphene composites grown at different temperatures and times were investigated by microscopes Raman spectrometer (inVia, Renishaw, England).

\section{Results and Discussion}

The CV curve at a potential scan rate of $100 \mathrm{mV} / \mathrm{s}$ in a $6 \mathrm{M} \mathrm{KOH}$ solution for carbon nanotube/graphene composites grown by one-step CVD for $10 \mathrm{~min}$ at $850^{\circ} \mathrm{C}$ is shown in Figure 1, which exhibits a nearly rectangular shape.

Figure 2 shows the effects of carbon nanotube/graphene composites grown by one-step CVD for $10 \mathrm{~min}$ at different growing temperatures $\left(850,900\right.$, and $\left.950^{\circ} \mathrm{C}\right)$ on specific capacitance. Carbon nanotube/graphene composites grown by one-step CVD at $850^{\circ} \mathrm{C}$ possessed the highest specific capacitance (see Figure 2). The reason behind this behavior may be explained as follows. The lower the growing temperature, the larger the $I_{\mathrm{D}} / I_{\mathrm{G}}$ (see Figure 3 ) due to a higher packing density of CNTs (possessing more defects than graphene) at a lower growing temperature (see Figure 4 and Table 1). A similar result (the density of CNTs can be controlled by the

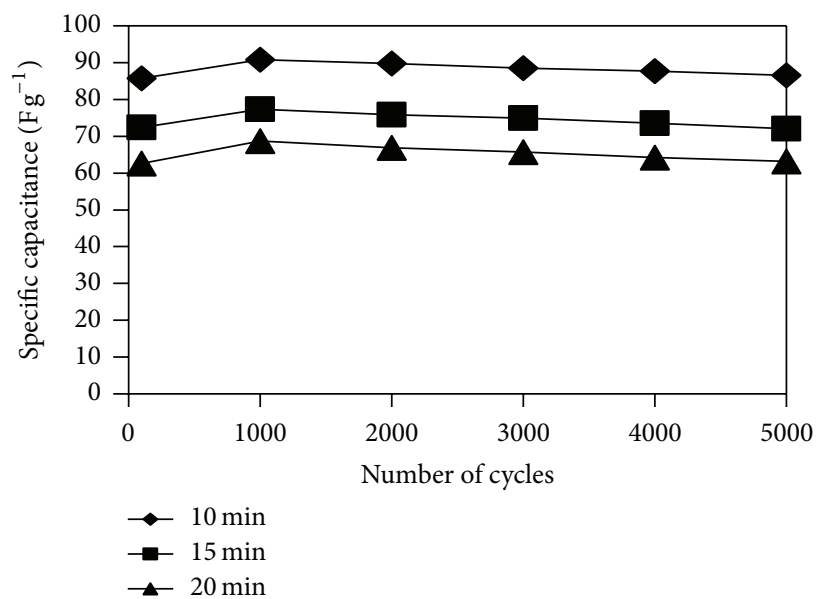

FIGURE 5: The effects of carbon nanotube/graphene composites grown by one-step CVD at $850^{\circ} \mathrm{C}$ for different growing times (10, 15 , and $20 \mathrm{~min}$ ) on specific capacitance.

CVD growth temperature) has been published in previous literature [31]. The $I_{\mathrm{D}} / I_{\mathrm{G}}(0.427)$ for carbon nanotube/graphene composites grown by one-step $\mathrm{CVD}$ at $850^{\circ} \mathrm{C}$ is larger than others $(0.388$ and 0.206$)$. The larger the $I_{\mathrm{D}} / I_{\mathrm{G}}$, the more the defect of carbon nanotube/graphene composites [21] and then the higher the surface area of carbon nanotube/graphene composites, which led to increasing the specific capacitance 


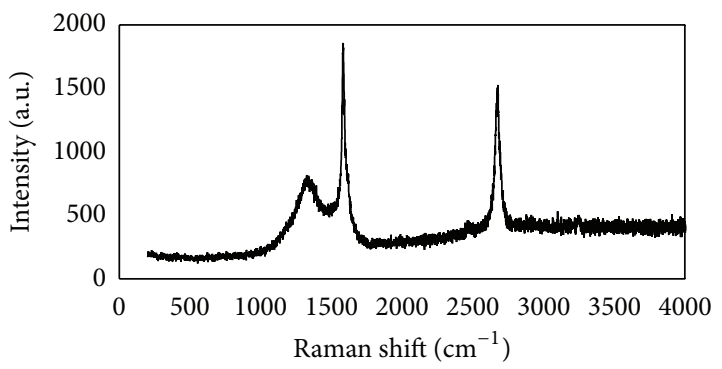

(a)

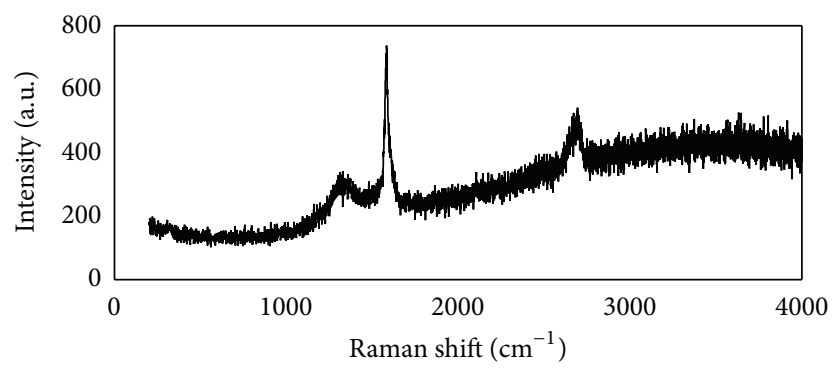

(b)

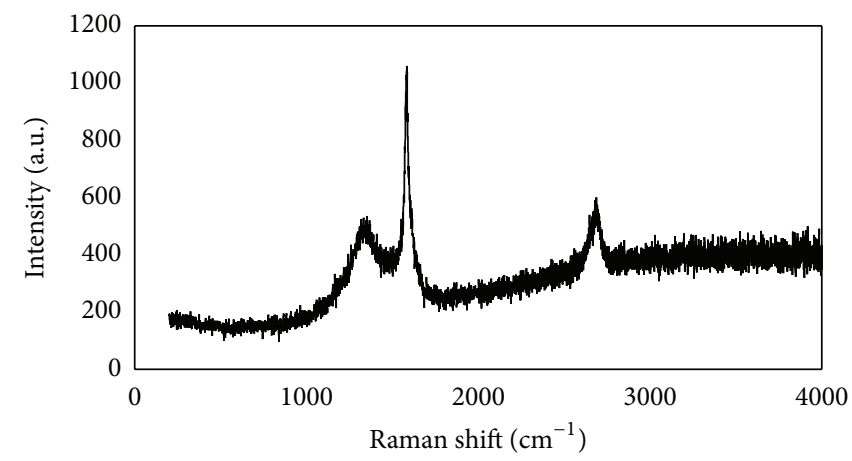

(c)

FIGURE 6: Raman spectra of carbon nanotube/graphene composites grown by one-step CVD at $850^{\circ} \mathrm{C}$ for different growing times ((a) 10 min, (b) $15 \mathrm{~min}$, and (c) $20 \mathrm{~min}$ ).

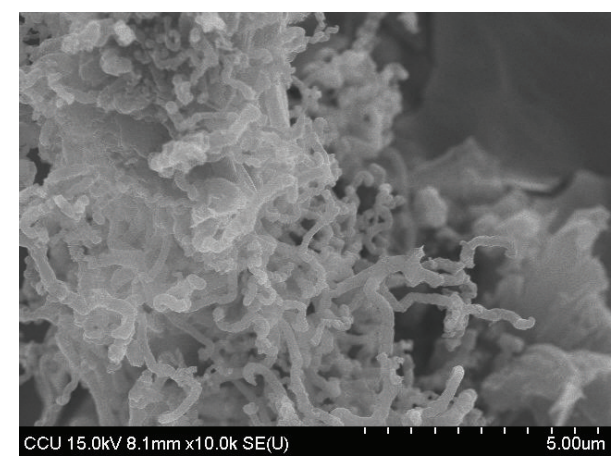

(a)

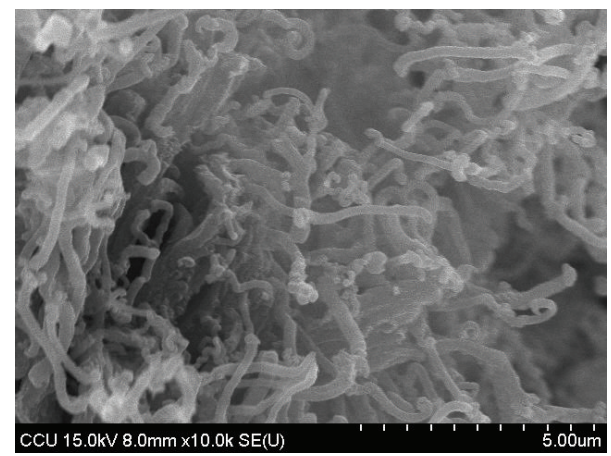

(b)

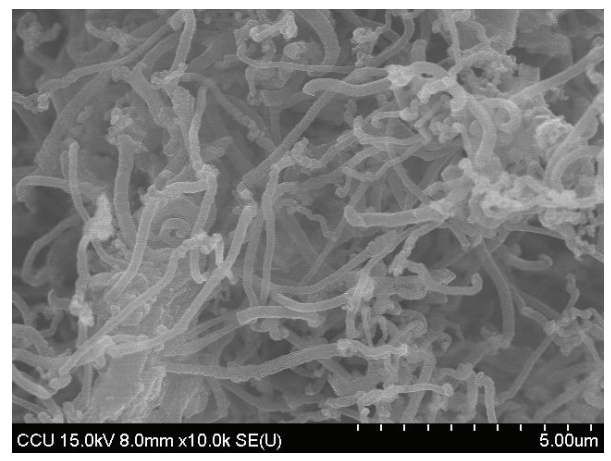

(c)

FIGURE 7: The FESEM images of carbon nanotube/graphene composites grown by one-step CVD at $850^{\circ} \mathrm{C}$ for different growing times ((a) $10 \mathrm{~min}$, (b) $15 \mathrm{~min}$, and (c) $20 \mathrm{~min}$ ). 
TABLE 1: The carbon nanotube packing density (calculated from Figures 4 and 7) of carbon nanotube/graphene composites grown by one-step CVD at different growing temperatures and times.

\begin{tabular}{lc}
\hline $\begin{array}{l}\text { Carbon nanotube/graphene } \\
\text { composites growing conditions }\end{array}$ & $\begin{array}{c}\text { Carbon nanotube } \\
\text { packing density, } \mathrm{cm}^{-2}\end{array}$ \\
\hline One-step CVD at $850^{\circ} \mathrm{C}$ for $10 \mathrm{~min}$ & $7.86 \times 10^{7}$ \\
One-step CVD at $900^{\circ} \mathrm{C}$ for $10 \mathrm{~min}$ & $9.34 \times 10^{6}$ \\
One-step CVD at $950^{\circ} \mathrm{C}$ for $10 \mathrm{~min}$ & $2.80 \times 10^{6}$ \\
One-step CVD at $850^{\circ} \mathrm{C}$ for $15 \mathrm{~min}$ & $8.06 \times 10^{8}$ \\
One-step CVD at $850^{\circ} \mathrm{C}$ for $20 \mathrm{~min}$ & $8.87 \times 10^{8}$ \\
\hline
\end{tabular}

for carbon nanotube/graphene composites grown by onestep CVD at $850^{\circ} \mathrm{C}$. Furthermore, the lower the growing temperature, the larger the $I_{2 \mathrm{D}} / I_{\mathrm{G}}$ (see Figure 3 ). The $I_{2 \mathrm{D}} / I_{\mathrm{G}}$ (0.826) for carbon nanotube/graphene composites grown by one-step $\mathrm{CVD}$ at $850^{\circ} \mathrm{C}$ is larger than others $(0.599$ and $0.578)$. The larger the $I_{2 \mathrm{D}} / I_{\mathrm{G}}$, the smaller the number of layers of graphene [19] and then the lighter the graphene weight, which also led to increasing the specific capacitance for carbon nanotube/graphene composites grown by one-step $\mathrm{CVD}$ at $850^{\circ} \mathrm{C}$. A similar result (thicker graphene results from a higher growth temperature) has been published in previous literature $[20,22]$.

Figure 5 shows the effects of carbon nanotube/graphene composites grown by one-step CVD at $850^{\circ} \mathrm{C}$ for different growing times $(10,15$, and $20 \mathrm{~min})$ on specific capacitance. Carbon nanotube/graphene composites grown by one-step CVD for $10 \mathrm{~min}$ possessed the highest specific capacitance (see Figure 5). The reason behind this behavior may be explained as follows. The shorter the growing time, the larger the $I_{2 \mathrm{D}} / I_{\mathrm{G}}$ (see Figure 6 ). The $I_{2 \mathrm{D}} / I_{\mathrm{G}}(0.826)$ for carbon nanotube/graphene composites grown by one-step CVD for $10 \mathrm{~min}$ is larger than others $(0.735$ and 0.568$)$. The larger the $I_{2 \mathrm{D}} / I_{\mathrm{G}}$, the smaller the number of layers of graphene [19] and then the lighter the graphene weight, which led to increasing the specific capacitance for carbon nanotube/graphene composites grown by one-step CVD for $10 \mathrm{~min}$. A similar result (thicker graphene results from a longer growth time) has been published in previous literature [22]. Furthermore, the $I_{\mathrm{D}} / I_{\mathrm{G}}(0.427)$ for carbon nanotube/graphene composites grown by one-step CVD for $10 \mathrm{~min}$ is a little smaller than others (0.448 and 0.493$)$ since the packing density of CNTs (possessing more defects than graphene) suddenly decreases with the decreasing growing time (see Figure 7 and Table 1) and even the average defect density for graphene increases with the decreasing growing time [21].

Figure 8 shows discharge curves of the carbon nanotube/graphene composite (grown by one-step CVD at $850^{\circ} \mathrm{C}$ for $10 \mathrm{~min}$ ) with different currents. The capacitance of the carbon nanotube/graphene composite was calculated from $C=i /[m(d E / d t)]$, where $m$ is the mass of the carbon nanotube/graphene composites, $i$ is the current, and $d E / d t$ is the slope of Figure 8. The capacitances as calculated by the above equation are shown in Figure 9. The lower the current, the higher the capacitance. The reason behind this behavior may be that the lower the current, the longer the discharge

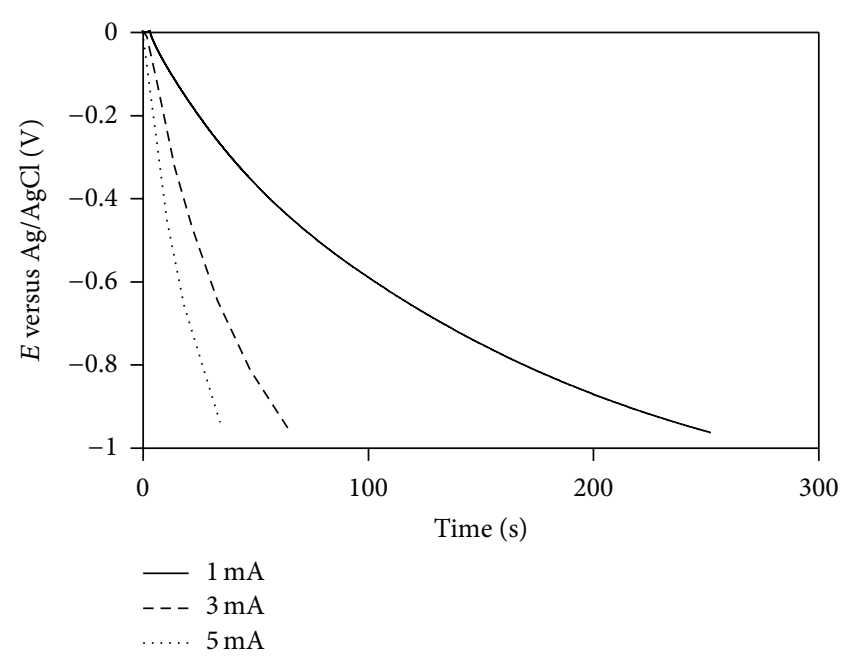

FIGURE 8: Discharge curves of the carbon nanotube/graphene composite (grown by one-step CVD at $850^{\circ} \mathrm{C}$ for $10 \mathrm{~min}$ ) with different currents.

time (see Figure 8), leading to higher capacitance due to $C=$ $i /[m(d E / d t)]$.

The $I_{\mathrm{G}} / I_{2 \mathrm{D}}$ for the carbon nanotube/graphene composite grown for $10 \mathrm{~min}$ at $850^{\circ} \mathrm{C}$ is about equal to 1.21 (see Figure 3(a)). The number of layers of the graphene for the carbon nanotube/graphene composite is about 20 [38]. The thickness of single-layer graphene is about $0.34 \mathrm{~nm}$ [39] and the interlayer distance between the graphene sheets is about $0.35 \mathrm{~nm}$ [40]. According to the above data, the thickness $(13.45 \mathrm{~nm})$ of the graphene for the carbon nanotube/graphene composite can be estimated. The thickness of the carbon nanotubes for the carbon nanotube/graphene composite is about $3.02 \mu \mathrm{m}$ (see Figure 10). So the thickness of the carbon nanotube/graphene composite grown on $\mathrm{Ni}$ foam for $10 \mathrm{~min}$ at $850^{\circ} \mathrm{C}$ is about $3.03345 \mu \mathrm{m}$. Furthermore, the area of the substrate (nickel foam) is $2 \mathrm{~cm}^{2}$. Then the volume of the carbon nanotube/graphene composite is $6.0669 \times 10^{-4} \mathrm{~cm}^{3}$. Therefore, the gravimetric capacitance $\left(90.79 \mathrm{~F} \mathrm{~g}^{-1}\right.$, please see at $850^{\circ} \mathrm{C}$ and 1000 cycles of Figure 2 of the revised paper) of the carbon nanotube/graphene composite $(0.008 \mathrm{~g})$ can be converted into the volumetric capacitance $\left(1197 \mathrm{~F} \mathrm{~cm}^{-3}\right)$.

\section{Conclusions}

The lower the growing temperature, the larger the $I_{\mathrm{D}} / I_{\mathrm{G}}$ and then the more the defect, the higher the surface area, which led to increasing specific capacitance. The lower the growing temperature, the larger the $I_{2 \mathrm{D}} / I_{\mathrm{G}}$, and then the smaller the number of layers of graphene, the lighter the graphene weight, which also led to increasing specific capacitance. Furthermore, the shorter the growing time, the larger the $I_{2 \mathrm{D}} / I_{\mathrm{G}}$, and then the smaller the number of layers of graphene, the lighter the graphene weight, which led to increasing specific capacitance. 


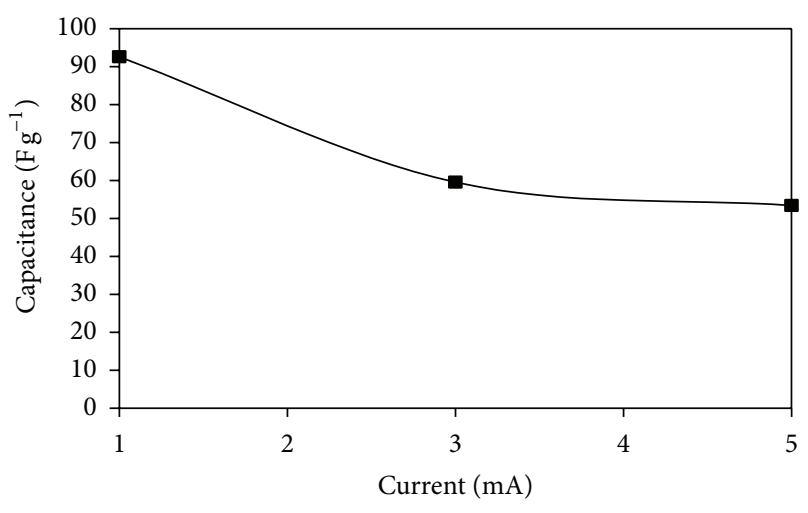

FIGURE 9: The effects of CP currents on specific capacitance of the carbon nanotube/graphene composite grown by one-step CVD at $850^{\circ} \mathrm{C}$ for $10 \mathrm{~min}$.

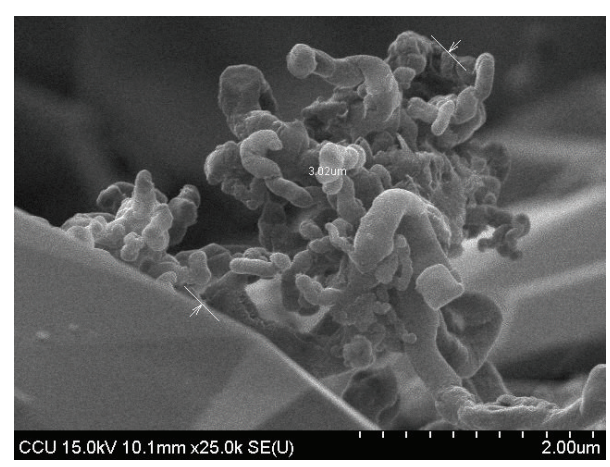

FIgURE 10: Cross-sectional morphology of the carbon nanotube/ graphene composite grown on Co-coated nickel foam by one-step $\mathrm{CVD}$ at $850^{\circ} \mathrm{C}$ for $10 \mathrm{~min}$.

\section{Conflict of Interests}

The authors declare that there is no conflict of interests regarding the publication of this paper.

\section{Acknowledgment}

Financial support by the National Science Council of the Republic of China (under Grant no. NSC 103-2221-E -224061-) is gratefully acknowledged.

\section{References}

[1] B. E. Conway, Electrochemical Supercapacitors-Scientific Fundamentals and Technological Applications, Kluwer Academic/ Plenum, New York, NY, USA, 1999.

[2] R. Kötz and M. Carlen, "Principles and applications of electrochemical capacitors," Electrochimica Acta, vol. 45, no. 15-16, pp. 2483-2498, 2000.

[3] Y. S. Chen and C. C. Hu, "Capacitive characteristics of binary manganese-nickel oxides prepared by anodic deposition," Electrochemical and Solid-State Letters, vol. 6, no. 10, pp. A210-A213, 2003.

[4] Y. U. Jeong and A. Manthiram, "Nanocrystalline manganese oxides for electrochemical capacitors with neutral electrolytes,"
Journal of the Electrochemical Society, vol. 149, no. 11, pp. A1419A1422, 2002.

[5] C.-C. $\mathrm{Hu}$ and C.-C. Wang, "Nanostructures and capacitive characteristics of hydrous manganese oxide prepared by electrochemical deposition," Journal of the Electrochemical Society, vol. 150, no. 8, pp. A1079-A1084, 2003.

[6] J. H. Park, O. O. Park, K. H. Shin, C. S. Jin, and J. H. Kim, "An electrochemical capacitor based on a $\mathrm{Ni}(\mathrm{OH})_{2}$ /activated carbon composite electrode," Electrochemical and Solid-State Letters, vol. 5, no. 2, pp. H7-H10, 2002.

[7] R. N. Reddy and R. G. Reddy, "Sol-gel $\mathrm{MnO}_{2}$ as an electrode material for electrochemical capacitors," Journal of Power Sources, vol. 124, no. 1, pp. 330-337, 2003.

[8] A. Burke, "Ultracapacitors: why, how, and where is the technology," Journal of Power Sources, vol. 91, no. 1, pp. 37-50, 2000.

[9] J.-K. Chang, C.-T. Lin, and W.-T. Tsai, "Manganese oxide/ carbon composite electrodes for electrochemical capacitors," Electrochemistry Communications, vol. 6, no. 7, pp. 666-671, 2004.

[10] M. S. Hong, S. H. Lee, and S. W. Kim, "Use of $\mathrm{KCl}$ aqueous electrolyte for $2 \mathrm{~V}$ manganese oxide/activated carbon hybrid capacitor," Electrochemical and Solid-State Letters, vol. 5, no. 10, pp. A227-A230, 2002.

[11] J. H. Park, J. M. Ko, and O. O. Park, "Carbon nanotube $/ \mathrm{RuO}_{2}$ nanocomposite electrodes for supercapacitors," Journal of the Electrochemical Society, vol. 150, no. 7, pp. A864-A867, 2003.

[12] J.-R. Zhang, B. Chen, W.-K. Li, J.-J. Zhu, and L.-P. Jiang, "Electrochemical behavior of amorphous hydrous ruthenium oxide/active carbon composite electrodes for super-capacitor," International Journal of Modern Physics B, vol. 16, no. 28-29, pp. 4479-4483, 2002.

[13] J. H. Chen, W. Z. Li, D. Z. Wang, S. X. Yang, J. G. Wen, and Z. F. Ren, "Electrochemical characterization of carbon nanotubes as electrode in electrochemical double-layer capacitors," Carbon, vol. 40, no. 8, pp. 1193-1197, 2002.

[14] P. Simon and Y. Gogotsi, "Capacitive energy storage in nanostructured carbon-electrolyte systems," Accounts of Chemical Research, vol. 46, no. 5, pp. 1094-1103, 2013.

[15] S. J. Chae, F. Güneş, K. K. Kim et al., "Synthesis of large-area graphene layers on poly-nickel substrate by chemical vapor deposition: wrinkle formation," Advanced Materials, vol. 21, no. 22, pp. 2328-2333, 2009.

[16] N. R. Franklin, Q. Wang, T. W. Tombler, A. Javey, M. Shim, and H. Dai, "Integration of suspended carbon nanotube arrays into electronic devices and electromechanical systems," Applied Physics Letters, vol. 81, no. 5, pp. 913-915, 2002.

[17] C. J. Lee, J. Park, and J. A. Yu, "Catalyst effect on carbon nanotubes synthesized by thermal chemical vapor deposition," Chemical Physics Letters, vol. 360, no. 3-4, pp. 250-255, 2002.

[18] H.-A. Ichi-oka, N.-O. Higashi, Y. Yamada, T. Miyake, and T. Suzuki, "Carbon nanotube and nanofiber syntheses by the decomposition of methane on group 8-10 metal-loaded $\mathrm{MgO}$ catalysts," Diamond and Related Materials, vol. 16, no. 4-7, pp. 1121-1125, 2007.

[19] W. Chen, Z. Fan, G. Zeng, and Z. Lai, "Layer-dependent supercapacitance of graphene films grown by chemical vapor deposition on nickel foam," Journal of Power Sources, vol. 225, pp. 251-256, 2013.

[20] W. Liu, C.-H. Chung, C.-Q. Miao et al., "Chemical vapor deposition of large area few layer graphene on $\mathrm{Si}$ catalyzed with nickel films," Thin Solid Films, vol. 518, no. 6, pp. S128-S132, 2010. 
[21] A. Umair and H. Raza, "Controlled synthesis of bilayer graphene on nickel," Nanoscale Research Letters, vol. 7, article 437, 2012.

[22] Z. Tu, Z. Liu, Y. Li et al., "Controllable growth of 1-7 layers of graphene by chemical vapour deposition," Carbon, vol. 73, pp. 252-258, 2014.

[23] E. J. Yoo, J. Kim, E. Hosono, H.-S. Zhou, T. Kudo, and I. Honma, "Large reversible Li storage of graphene nanosheet families for use in rechargeable lithium ion batteries," Nano Letters, vol. 8, no. 8, pp. 2277-2282, 2008.

[24] Y. Wang, Y. Wu, Y. Huang et al., "Preventing graphene sheets from restacking for high-capacitance performance," The Journal of Physical Chemistry C, vol. 115, no. 46, pp. 23192-23197, 2011.

[25] X. Lu, H. Dou, B. Gao et al., "A flexible graphene/multiwalled carbon nanotube film as a high performance electrode material for supercapacitors," Electrochimica Acta, vol. 56, no. 14, pp. 5115-5121, 2011

[26] Z. Fan, J. Yan, L. Zhi et al., "A three-dimensional carbon nanotube/graphene sandwich and its application as electrode in supercapacitors," Advanced Materials, vol. 22, pp. 3723-3728, 2010 .

[27] Z. J. Fan, J. Yan, T. Wei et al., "Nanographene-constructed carbon nanofibers grown on graphene sheets by chemical vapor deposition: high-performance anode materials for lithium ion batteries," ACS Nano, vol. 5, no. 4, pp. 2787-2794, 2011.

[28] S. Li, Y. Luo, W. Lv et al., "Vertically aligned carbon nanotubes grown on graphene paper as electrodes in lithium-ion batteries and dye-sensitized solar cells," Advanced Energy Materials, vol. 1, no. 4, pp. 486-490, 2011.

[29] W. Wang, S. Guo, M. Penchev et al., "Hybrid low resistance ultracapacitor electrodes based on 1-pyrenebutyric acid functionalized centimeter-scale graphene sheets," Journal of Nanoscience and Nanotechnology, vol. 12, no. 9, pp. 6913-6920, 2012.

[30] W. Wang, I. Ruiz, S. Guo et al., "Hybrid carbon nanotube and graphene nanostructures for lithium ion battery anodes," Nano Energy, vol. 3, pp. 113-118, 2014.

[31] X. Dong, B. Li, A. Wei et al., "One-step growth of graphenecarbon nanotube hybrid materials by chemical vapor deposition," Carbon, vol. 49, no. 9, pp. 2944-2949, 2011.

[32] M. Ghazinejad, S. Guo, R. K. Paul et al., "Synthesis of grapheneCNT hybrid nanostructures," Materials Research Society Proceedings, vol. 1344, pp. 23-27, 2011.

[33] Rajesh, R. K. Paul, and A. Mulchandani, "Platinum nanoflowers decorated three-dimensional graphene-carbon nanotubes hybrid with enhanced electrocatalytic activity," Journal of Power Sources, vol. 223, pp. 23-29, 2013.

[34] W. Wang, S. Guo, M. Penchev et al., "Three dimensional few layer graphene and carbon nanotube foam architectures for high fidelity supercapacitors," Nano Energy, vol. 2, no. 2, pp. 294-303, 2013.

[35] T. Xiao, X. Hu, B. Heng et al., "Ni(OH $)_{2}$ nanosheets grown on graphene-coated nickel foam for high-performance pseudocapacitors," Journal of Alloys and Compounds, vol. 549, pp. 147-151, 2013.

[36] Y. Wang, A. Yuan, and X. Wang, "Pseudocapacitive behaviors of nanostructured manganese dioxide/carbon nanotubes composite electrodes in mild aqueous electrolytes: effects of electrolytes and current collectors," Journal of Solid State Electrochemistry, vol. 12, no. 9, pp. 1101-1107, 2008.
[37] Y. Tian, J.-W. Yan, R. Xue, and B.-L. Yi, "Influence of electrolyte concentration and temperature on the capacitance of activated carbon," Acta Physico-Chimica Sinica, vol. 27, no. 2, pp. 479485, 2011.

[38] A. Das, B. Chakraborty, and A. K. Sood, "Raman spectroscopy of graphene on different substrates and influence of defects," Bulletin of Materials Science, vol. 31, no. 3, pp. 579-584, 2008.

[39] J. I. Parades, S. Villar-Rodil, A. Martínez-Alonso, and J. M. D. Tascón, "Graphene oxide dispersions in organic solvents," Langmuir, vol. 24, no. 19, pp. 10560-10564, 2008.

[40] A. Reina, X. Jia, J. Ho et al., "Large area, few-layer graphene films on arbitrary substrates by chemical vapor deposition," Nano Letters, vol. 9, no. 1, pp. 30-35, 2009. 

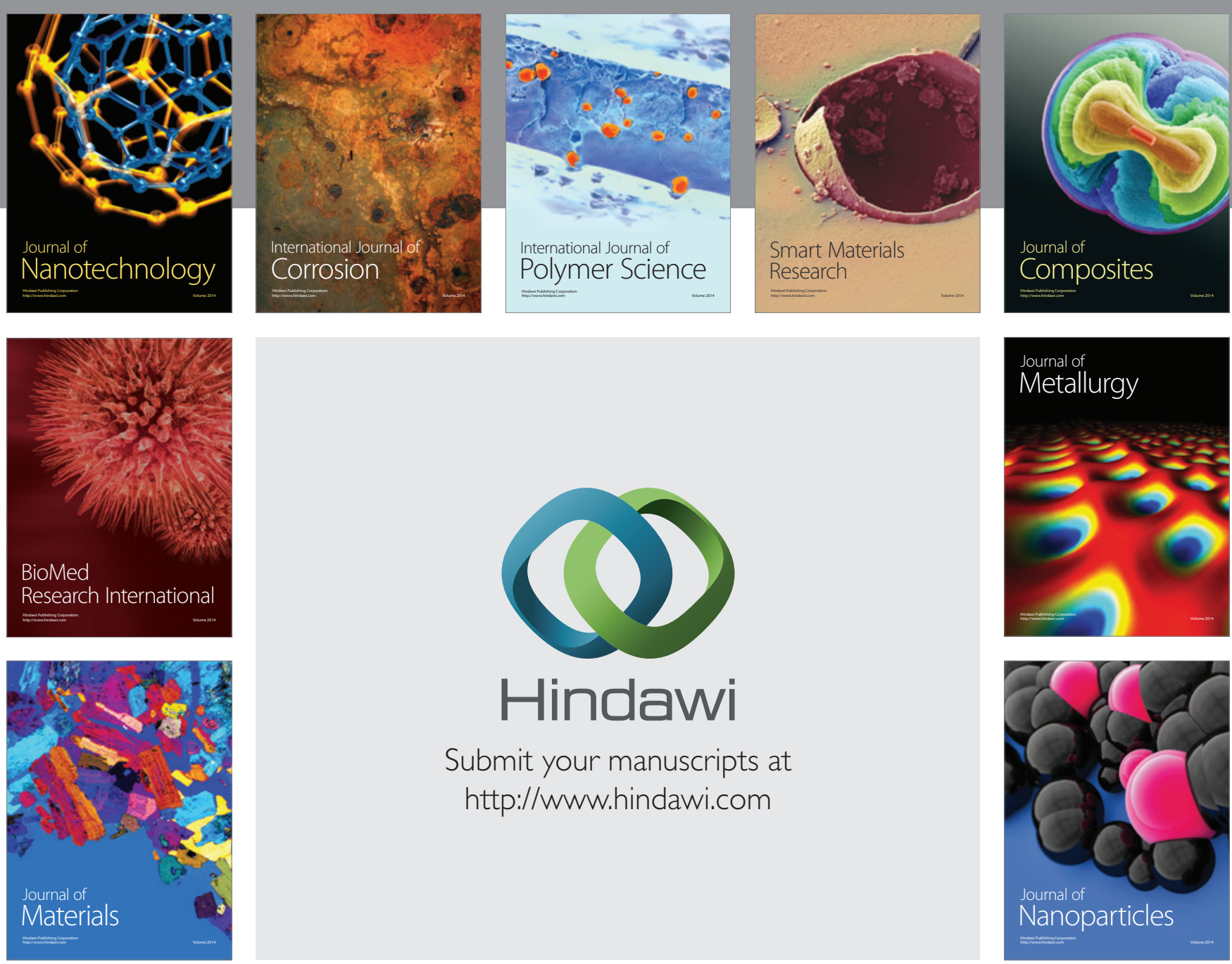

Submit your manuscripts at http://www.hindawi.com
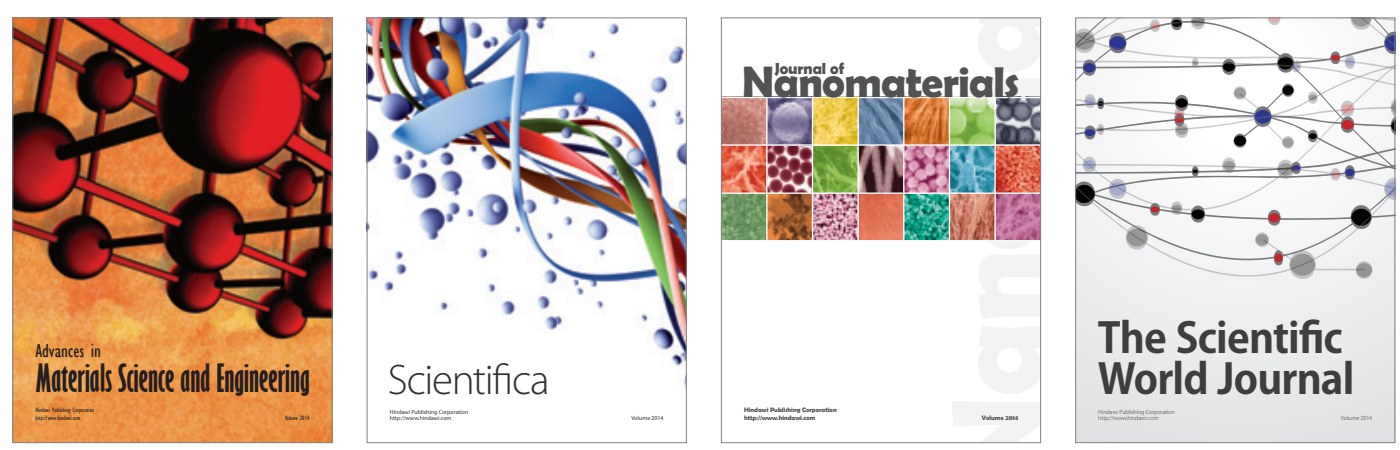

\section{The Scientific World Journal}
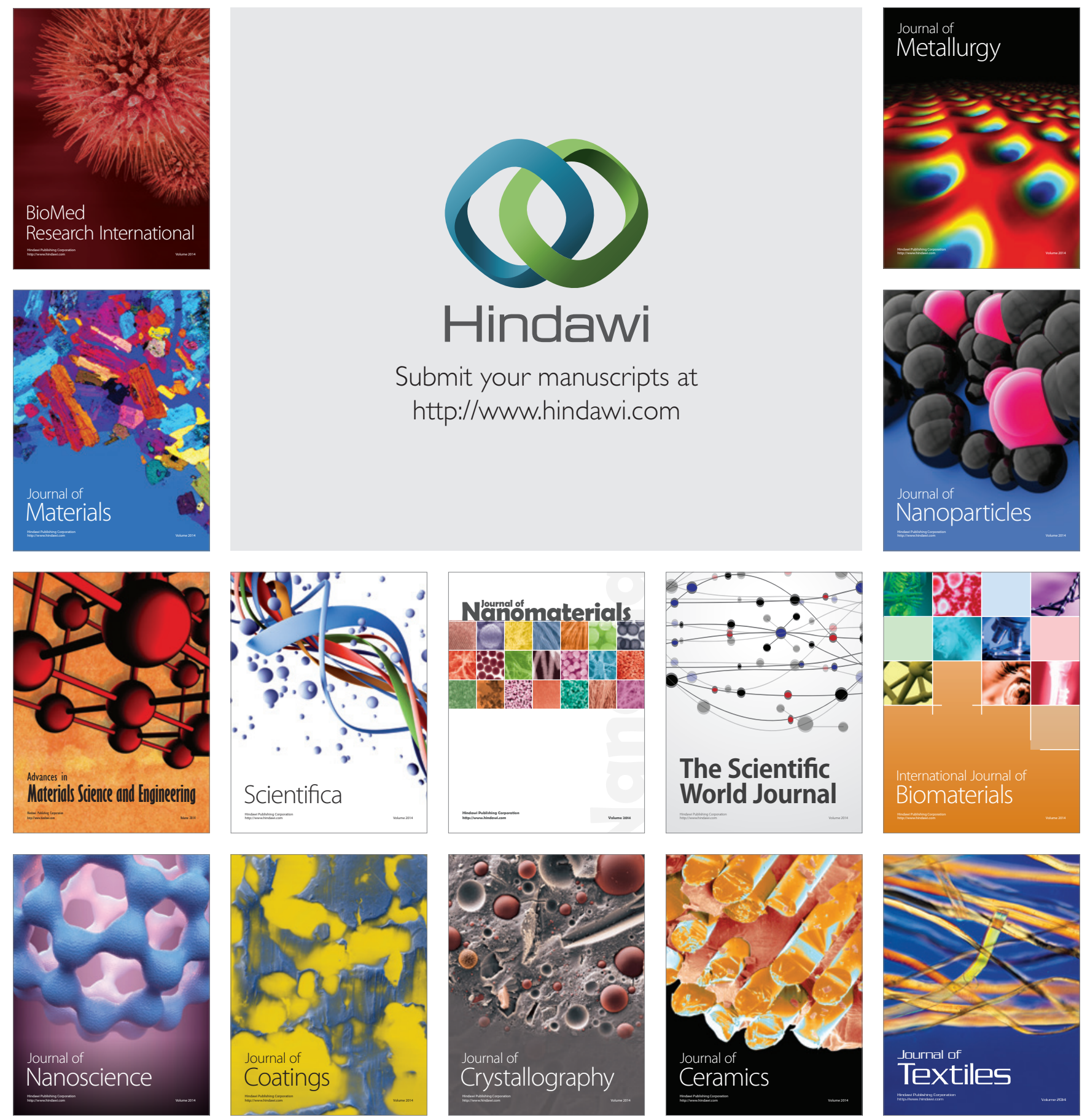